\title{
BEST PRACTICES
}

Journal of Communication Pedagogy
2019, Vol. 2, 111-118
O The Author(s) 2019
$\begin{array}{r}\text { COMMUNAL OF } \\ \text { PEDACOCYIION }\end{array}$
Reprints and permissions: http://www.csca-net.org
DOI:10.31446/JCP.2019.20
Central States Communication Association

\section{Best Practices for Teaching Discussion as Part of High School Common Core State Standards}

\author{
Mitchell Stengel, Leah Nolan, David Donnick, Wesley Skym, and Anna M. Wright
}

Keywords: classroom discussion, Common Core State Standards, secondary education, participation

\begin{abstract}
Instructional discussion is a teaching method used in many classrooms across grade levels. In fact, the Common Core State Standards promote the use of instructional discussion in secondary classrooms (Common Core State Standards Initiative, 2018a). Students, however, are not always taught best practices for engaging in a discussion and may feel unprepared to participate. As a result, discussions may not produce the dynamic learning opportunity they are intended to foster. This essay provides 10 tips for high school teachers to prepare students in the high school classroom to engage in a meaningful classroom discussion effectively in order to ensure students are learning and are engaged in a productive manner while meeting the demands of the Common Core Standards.
\end{abstract}

When discussing and researching the teaching of communication, high school classrooms are often neglected. This neglect is unfortunate because the Common Core State Standards (CCSS) place an emphasis on Speaking and Listening in the K-12 curriculum. The CCSS were developed through a collaborative effort of educators (Common Core State Standards Initiative, 2018a) and have been adopted by 41 states, the District of Columbia, four territories, and the Department of Defense (Common Core State Standards Initiative, 2018b). Accordingly, although many high school students are being taught speaking and listening skills to some extent, not all teachers are adequately trained or held accountable for teaching the standards (Wright, Rohman, Horn, Meyer, \& Simonds, 2018), making the impetus for implementing communication pedagogy in $\mathrm{K}-12$ schools even more paramount.

Mitchell Stengel, Leah Nolan, David Donnick, Wesley Skym, and Anna M. Wright, Illinois State University, Normal, IL CONTACT: amwright@ilstu.edu 
The Speaking and Listening strand of the CCSS for English Language Arts has a focus on the use of instructional discussion. Within this strand, a standard titled Comprehension and Collaboration focuses on preparing for and participating in conversations with diverse individuals (Common Core State Standards Initiative, 2018a). The grade 9-12 standards include skills such as "propel conversations by posing and responding to questions," "respond thoughtfully to diverse perspectives," and "work with peers to promote civil, democratic discussions" (Common Core State Standards Initiative, 2018a, p. 50). Although teachers often require students to participate in instructional discussions, they seldom teach students how to engage in those discussions, including the aforementioned specific skills. If they did teach students to engage in instructional discussions, it could help prepare students to meet most of the Speaking and Listening standards. Although scholarship exists that highlights how teachers should facilitate an instructional discussion (Anderson, Nussbaum, Pecchioni, \& Grant, 1999; Simonds, Wright, \& Cooper, 2019) and how discussion occurs in problem-solving groups (Beebe \& Masterson, 2012; Rothwell, 2019), there is a lack of resources for secondary educators on how to teach students to engage in instructional discussion (Larson, 2000). Therefore, this Best Practices article provides tips for high school teachers to use in order to prepare their students to engage in meaningful instructional discussions.

\section{Best Practice \#1: Introduce the Purpose of Discussion}

Students are more likely to participate in discussion if they understand the purpose of the current discussion as well as the discussion construct in general. Brookfield and Preskill (2012) described four purposes of discussion, which include a better-informed understanding of a topic, increased selfawareness, an appreciation for the variety of opinions shared in a discussion, and a means to inspire taking informed action. Similarly, Phillips (1966) suggested that learning effective participation in small groups enables individuals to influence decision-making in society. Further, he asserted that in education, the use of discussion groups allows students and teachers to apply what they are learning as well as master content. The CCSS require students to be able to discuss with diverse partners and synthesize and respond to diverse perspectives. As such, high school educators should explain to students that discussion is a way to learn content, understand different perspectives, and discuss ideas in a comfortable, safe space designed to foster learning. In doing so, students will be better prepared to participate in small groups that will help them influence their world. To ensure a variety of opinions and shared ideas, teachers should explain that students do not have to agree with everything that is said, but that they should use the discussion as a learning opportunity.

\section{Best Practice \#2: Create a Comfortable Atmosphere}

To learn from and respond to diverse opinions, students must first feel comfortable sharing their ideas. Brookfield and Preskill (2012) suggested that when promoting democratic discussions, teachers should place an emphasis on collaboration and respect. They noted that their experiences getting students to embrace this emphasis has been challenging; however, they found that teacher promotions of appropriate dispositions moves students in the right direction. These dispositions include hospitality, mindfulness, humility, and appreciation. Hospitality refers to creating an environment where people want to participate and are encouraged to take risks, mindfulness is paying close attention to what others are saying, humility expresses an ability to admit that knowledge is limited, and appreciation refers to acknowledging when someone has an insightful contribution or idea through feedback and commentary. This list is not exhaustive, but provides a basis for creating a comfortable space for sharing ideas and experiences. 
Further, Gibb (1961) developed categories of communication that create defensive and supportive climates. He argued that a defensive climate is created by judgmental statements, lack of concern for others' well-being, and attitudes of superiority. Conversely, he suggested that using non-evaluative language, showing empathy, and investigating issues rather than taking a strong stance are all communication behaviors that promote a supportive communication climate. Teachers can promote these supportive communication behaviors in a number of ways, but the goal is for teachers to deliberately work toward creating an environment of mutual learning and ensuring that students enter discussions hopeful of either learning something new or acknowledging a new viewpoint.

\section{Best Practice \#3: Utilize Student Choice}

Another way to encourage a comfortable discussion environment is to promote student choice through student-guided discussions. Giving students opportunities to make choices in the classroom will lead to intrinsic motivation and feelings of self-efficacy (Brooks \& Young, 2011). In fact, the CCSS assert that students should work with peers to decide upon rules for a discussion. Teachers can have students work with peers to create their own rules and guidelines for all classroom discussions. Beebe and Masterson (2012) suggested that small groups develop ground rules, which are clear guidelines of acceptable behavior that group members agree upon. Teachers should allow students to decide what rules need to be explicitly stated to ensure the discussion moves forward how they wish. Larson (2000) mentioned that there is some flexibility regarding rules, stating, "other than a requirement to listen and respect their classmates' rights to share their opinions and ideas, these teachers often do not teach a specific list of do's and don'ts. They emphasize the intent of rules, rather than the rules themselves" (p. 673); therefore, this is a good area for teachers to implement student choice and responsibility. Teachers should allow students to take ownership of rules for participation in discussion to foster a student-centered learning environment. Additionally, when students are facilitating the discussion, they should be allowed to determine the path the discussion follows. Teachers should allow students to ask questions, so the discussion reflects what they deem important. Inherently, this not only introduces effective student choice, but also helps to make the conversation student-driven.

\section{Best Practice \#4: Teach Through Modeling}

The CCSS require students to be able to ask their own questions and propel the discussion themselves. As such, modeling is a crucial component of the discussion process. Often, the best way to learn what a good discussion looks and sounds like is to view a discussion from the outside, which can happen in a number of ways. First, because teachers are the constant model for classroom discussion, teachers should model good listening, respect for other viewpoints, and appropriate question-asking techniques. As Larson (2000) explained, "if discussion is to be used as a way to help students construct knowledge and to help students learn how to go about the process of discussing, then the teachers are a crucial variable in creating such a context" (p. 663). In their study on student participation in the basic course, Meyer and Hunt (2011) reported that students felt that positive teacher feedback and nonverbal cues were influential to their in-class participation. Similarly, Simonds, et al. (2019) found that a teacher's reaction to student responses can either "stifle or enhance the discussion process" (p. 161). As such, they recommend teachers praise rather than criticize, encourage student input with questions such as "What does everyone else think of that?," and deliberately communicate their communication choices so that all students understand what is being said. 
Accordingly, teachers should model these behaviors and identify them to students so that students can mirror them during their discussions. Further, if teachers wish to move to a more student-centered discussion, they can teach students to lead discussions by modeling a teacher-led discussion first (Haston, 2007). We recommend teachers begin with a teacher-led discussion and then slowly reduce their presence in the discussion environment. Students can also watch a discussion from the outside and learn from it by engaging in discussion techniques such as holding a Socratic Seminar, where an inner circle discusses content of the text being used while the outer circle discusses the functions of the inner circle's discussion itself (e.g., the dynamics, the flow, the usage of references). Teachers then can facilitate a discussion of what students observed that made a productive or unproductive discussion (somewhat of a meta-discussion).

\section{Best Practice \#5: Teach Preparation}

Once certain parameters have been established and students have observed the teacher modeling effective discussion behaviors, there are certain skills that students need to learn in order to participate in effective, collaborative, and purposeful discussion. The CCSS (2018a) ask students to "come to discussions prepared, having read and researched the material under study" (p. 50), which means that students should come to class with an understanding of the content that will be discussed and be prepared to engage in a conversation that applies that content beyond simple recall. One important piece of a discussion, especially once students become familiar with the process, is that they should be student-run. Simonds, Hooker, and Wright (2015) explained that when students come to class prepared, the class inherently becomes student-centered. Preparation allows students to hold a stake in the conversation, bringing their own knowledge and experiences to the forefront of the discussion as well as to the forefront of their own learning. Preparation creates low-risk opportunities for students to jot down their own notes, thoughts, and experiences beforehand, allowing them to be less apprehensive to speak during the discussion.

This preparation can take many forms, such as completing anticipation guides, giving students possible prompts the day before the discussion, or having students write questions as they read so the students will have pre-prepared, low-risk opportunities to speak. Rattenborg, Simonds, and Hunt (2005) found that reading objectives and preparation prompts help provide the framework for discussion and aid in the comprehension of the content itself. Reading prompts serve as the content knowledge for the discussion, whereas discussion prompts ask students to engage in higher-order thinking (Simonds, et al., 2019). This way, students are aided not only in the transmission of content knowledge, but also, they have constructive scaffolding needed to participate in the discussion. Therefore, teachers should have a mechanism in place to have students come with notes or discussion prompts that prepare them to participate in the discussion in a low-risk manner.

\section{Best Practice \#6: Teach Active Listening}

The CCSS require students to be able to respond to information presented in a variety of formats, including orally. To be able to respond, students must be able to take the information they have heard, effectively interpret the information, and formulate a coherent response. Inherently, this involves the instruction of listening. Best practices for teaching listening require interaction, encoding, and explicitly demonstrating skills to be a good listener. These quality active listening techniques involve nonverbal gestures and expressions, reflecting the message back to the speaker (Spataro \& Bloch, 2018). Additionally, Simonds, et al. (2019) suggest teaching paraphrasing (i.e., restating the information and emotion in a 
message), teaching question-asking, and helping students understand that listening is culturally-bound. Teaching listening involves the explicit demonstration of these tactics in everyday interaction, especially when students are answering questions or while having conversations. When teaching students to listen, teachers should focus on helping them listen with the intent to respond to what is stated. An ample way to teach students to listen is to inform students about active listening strategies through readings or lecture and then give them opportunities to practice these active listening strategies that are necessary for discussions to work within the walls of a classroom.

\section{Best Practice \#7: Teach Question-Asking}

The CCSS require students to be able to propel conversations by posing questions, which means that students need to be taught appropriate question-asking techniques. Throughout the day, teachers should engage in question-asking techniques in order to model how students should ask questions in their own discussions. It also would be effective for teachers to demonstrate the facilitation of a discussion, modeling effective question-asking techniques during the discussion. The teacher can take time during teacher-led discussions to explain how they structured questions and why. Simonds, et al. (2019) suggest using Bloom's taxonomy to construct questions that vary in difficulty and work to get students to higher-level thinking; this taxonomy and rationale can be shared with students to help them learn to ask questions that will advance the discussion. Similarly, Anderson et al. (1999) offered four types of questions that should be avoided: yes-no questions, questions that ask students to continue answering after they have somehow indicated they do not know an answer, questions that require students to guess, and leading questions. Teachers should inform students to use these question-asking techniques that they themselves have been using while avoiding inappropriate questions to make the discussion truly student-led.

\section{Best Practice \#8: Teach How to Cite Textual References}

One of the learning outcomes of instructional discussion is that students can use research or textual evidence to support claims. In fact, the CCSS (2018a) state that students should be able to refer to "evidence from texts and other research on the topic or issue to stimulate a thoughtful, well-reasoned exchange of ideas" (p. 50). Evidence is one of the most prominent ways students can increase their credibility within a discussion, particularly when the textual evidence reinforces their original ideas. Larson (2000) asserted that one purpose for questioning in discussion is to ensure students can use the best evidence they have available to respond to that question. Additionally, teaching students that citations increase credibility as a speaker is necessary to validate the use of textual references within discussion. Consequently, students must be taught how to use textual evidence in discussion. Presumably, students will have an understanding of how to cite sources in text; thus, a brief explanation of how that translates to an oral discussion is warranted. Basic communication course textbooks report inconsistent strategies for orally citing sources (Kinnick \& Holler, 2012); however, in alignment with the CCSS, students should be able to cite, at minimum, an author and the year the work was published if it is a reference the class has not collectively read. If the students are more advanced, an article title and publisher would be even more appropriate. If the class is collectively reading a text, students should cite page numbers so their classmates can follow their statement(s).

Students should be taught phrases that help them cite textual references such as "according to," "the text mentions," or "in my experience." Similarly, students may need to be taught paraphrasing skills in order to accurately incorporate their own phrasing of the author's work or another person's idea into 
classroom discussion. In a study designed to enhance students' use of oral citations in speeches, Buerkle and Gearhart (2017) created an online mastery training strategy. The online training asked students to read, among other content, a description of what constitutes plagiarism, elements of a citation, examples of different types of citations, and the use of paraphrasing when citing sources. Students who completed this training performed better on oral citations than those students who did not. In turn, teachers can provide students with examples and explain the importance of giving credit to sources as ways to help students complete their oral citations in discussion. If teachers want students to be able to accurately cite textual evidence and outside research, they must first teach them how to incorporate that information into the discussion.

\section{Best Practice \#9: Teach Improvisation Skills to Participate in Discussion}

A critical part of a student-centered discussion is the ability for students to use words and phrases in order to move a discussion forward. Best Practice \#5 recommended teaching students how to prepare to participate in an instructional discussion, but there are still skills needed to seamlessly carry out a discussion. The CCSS ask that students be able to respond to ideas in the moment to understand and engage in the larger discussion. Therefore, it is imperative that students learn improvisation skills in order to move the conversation forward and to connect their own ideas effectively. Improvisation skills help the discussion to move not only from topic to topic, but also from surface-level learning to deeper learning. Although improvisation is an important part of discussion, it does not come easily. It requires multiple sessions of teaching and a comfortable environment that allows for open and freeflowing discussion, which may include thoughts that have not been fully formed. Hickey (2009) argued that a classroom must be fit for improvisation, including an openness to diversity and students who are listening attentively.

There are ways that improvisation can be added to regular classroom content in order to prepare for discussion. For example, teaching students effective transitional words and phrases such as "to build on," "in addition to," or "I understand what you are saying; however, I disagree" will help students govern their own discussion and further it along. Additionally, impromptu speeches can help prepare students for the improvisation necessary in discussions. Having students listen to a stimulus and then orally respond to what they heard will prepare them to think in a manner conducive to the type of thinking required in instructional discussions. It is important for teachers to create many low-risk opportunities for students to practice their improvisation skills, especially when it comes to agreeing or disagreeing with others. These opportunities for improvisation help the conversation move along accordingly.

\section{Best Practice \#10: Vary Strategies to Create a Space for all Learners}

In order for an effective instructional discussion to occur, all students must be willing to participate. It is no surprise that using the discussion method in the classroom is met with pushback from students who are shy, students with communication apprehension, students with communication disabilities, or students who simply do not want to participate orally. This can create uncertainty on the part of the instructor regarding whether discussion should be implemented at all. To combat this, instructors should teach students about communication apprehension and the strategies needed to overcome it. Gall and Gillett (1980) argued that there are many ways to combat apprehension including modifying the size of the group and the manner in which students are engaged in the discussion. For example, not every discussion needs to be a full class discussion. There are a variety of discussion methods (e.g., The 
Fishbowl, Big Paper, Think-Pair-Share) that rely on smaller discussion groups and those groups provide more opportunities for different students to speak. Technology also can help facilitate instructional discussion. While some students discuss orally, other students can discuss in a back channel (similar to the Socratic Seminar mentioned in Best Practice \#4), but with a simultaneous conversation via technology. Because students come to classrooms with a variety of experiences and needs, it is important for instructors to make a comfortable space for all students to participate in classroom discussions. Further, teachers should consult with students with disabilities or their corresponding special education teachers regarding how they can accommodate them in discussions.

\section{Conclusion}

Instructional discussion provides a rich learning opportunity for students and teachers alike and it is important for both to be properly trained to participate in discussions. Specifically, instructional discussions allow students to be actively engaged in their learning, which enhances their learning (Simonds, et al., 2019), promotes critical thinking (Anderson et al., 1999; Simonds, et al.), and enhance their ability to influence change in their world (Phillips, 1966). Additionally, it creates a foundation for a strong high school communication course aligned with the CCSS. Because high school communication teachers often are ill-equipped to teach communication skills, these best practices provide teachers with ways to explicitly prepare students to communicate in discussions. Moreover, effectively teaching students to engage in instructional discussion lays the foundation for effectively meeting the Speaking and Listening Standards in the CCSS in a high school communication class.

\section{References}

Anderson, J., Nussbaum, J., Pecchioni, L., \& Grant, J. A. (1999). Interaction skills in instructional settings. In A. L. Vangelisti, J. A. Daly, G. W. Friedrick (Eds.), Teaching communication: Theory, research, and methods (2nd ed., pp. 359-374). Mahwah, NJ: Lawrence Erlbaum.

Beebe, S. A., \& Masterson, J. T. (2012). Communicating in small groups: Principles and practices (10th ed). Boston, MA: Pearson.

Brookfield, S. D., \& Preskill, S. (2012). Discussion as a way of teaching: Tools and techniques for democratic classrooms (2nd ed.). San Francisco, CA: Jossey and Bass.

Brooks, C. F., \& Young, S. L. (2011). Are choice-making opportunities needed in the classroom? Using Self-Determination Theory to consider student motivation and learner empowerment. International Journal of Teaching and Learning in Higher Education, 23, 48-59. Retrieved from http://www.isetl. org/ijtlhe/

Buerkle, C. W., \& Gearhart, C. C. (2017). Answer me these questions three: Using online training to improve students' oral source citation. Communication Teacher, 31, 47-61. doi:10.1080/17404622. 2016.1244351

Common Core State Standards Initiative. (2018a). English language arts standards. Retrieved from http://www.corestandards.org/wp-content/uploads/ELA_Standards1.pdf

Common Core State Standards Initiative. (2018b). Standards in your state. Retrieved from http://www. corestandards.org/standards-in-your-state/

Gall, M. D., \& Gillett, M. (1980). The discussion method in classroom teaching. Theory into Practice, 19, 98-103. doi:10.1080/00405848009542881

Gibb, J. R. (1961). Defensive communication. Journal of Communication, 11, 141-148. doi:10.1111/ j.1460-2466.1961.tb00344.x 
Haston, W. (2007). Teacher modeling as an effective teaching strategy. Music Educators Journal, 93, 26-30. doi:10.1177/002743210709300414

Hickey, M. (2009). Can improvisation be 'taught'? A call for free improvisation in our schools. International Journal of Music Education, 27, 285-299. doi:10.1177/0255761409345442

Kinnick, K. N., \& Holler, E. (2012). Conflicting advice on oral citations in top public speaking texts. Basic Communication Course Annual, 24, 1-35. Retrieved from https://ecommons.udayton.edu/bcca

Larson, B. E. (2000). Classroom discussion: A method of instruction and a curriculum outcome. Teaching and Teacher Education, 16, 661-677. doi:10.1016/S0742-051X(00)00013-5

Meyer, K. R., Hunt, S. K. (2011). Rethinking evaluation strategies for student participation. Basic Communication Course Annual, 23, 1-34. Retrieved from https://ecommons.udayton.edu/bcca

Phillips, G. M. (1966). Communication and the small group. Indianapolis, IN: Bobbs-Merrill.

Rattenborg, A. N., Simonds, C. J., \& Hunt, S. K. (2005). Preparing to participate: An exploration of student engagement through student work and instructor's observations. Basic Communication Course Annual, 17, 94-133. Retrieved from https://ecommons.udayton.edu/bcca

Rothwell, J. D. (2019). In mixed company: Communicating in small groups and teams (10th ed.). Boston, MA: Wadsworth Cengage Learning.

Simonds, C. J., Hooker, J. F., \& Wright, A. M. (2015). Instructional discussion: The most important area of training for new basic course instructors. Basic Course Communication Annual, 27, 32-42. Retrieved from https://ecommons.udayton.edu/bcca

Simonds, C. J., Wright, A. M., \& Cooper, P. J. (2019). Communication for teachers and trainers. Southlake, TX: Fountainhead.

Spataro, S. E., \& Bloch, J. (2018). “Can you repeat that?” Teaching active listening in management education. Journal of Management Education, 42, 168-198. doi:10.1177/1052562917748696

Wright, A. M., Rohman, B. M., Horn, D. C., Meyer, B., \& Simonds, C. J. (2018). Exploring the content and implementation of the Common Core State Standards in a high school and college level course. Basic Communication Course Annual, 30, 32-60. Retrieved from https://ecommons.udayton.edu/ bcca 